\title{
Primary Mesothelioma of the Fallopian Tube.
}

\author{
By Clara Eglington, M.B., B.S., \\ From the Pathological Department of the Leeds General Infirmary.
}

Ir seems well to place this case upon record, not only because, as a primary condition, tumours of the Fallopian tube are rare, but also because, in this instance, the histology is of great interest.

Clinical history. Mrs. B., aged 47, was admitted to the Leeds General Infirmary, under Dr. Hellier, in May 1911. She had been married twice, and had had two full-term pregnancies by her former husband, but none by the latter, to whom she had been married 20 years. She had "the bad disorder" (? gonorrhœa) during her first marriage. Menstruation ceased three years ago, and was previously unimportant. She has complained of a foetid, watery, vaginal discharge, often streaked with blood, for 13 years, which, however, has been much worse for 8-12 months, and of late has contained a considerable amount of blood. For 12 months she has had frequency of micturition and incontinence of urine, and whenever she has voluntarily emptied her bladder the vaginal discharge has been most copious. She gives a definite history of loss of weight for three months. Some four months ago she first noticed a discharge from the umbilicus which has persisted to the present time.

Operation. On May 6, $1911 \mathrm{Dr}$. Hellier operated and removed the left appendages, which he found enlarged and adherent to the posterior wall of the lower one-third of the uterus. The right appendages and the uterus appeared normal. Recovery was uneventful, and she was sent to a convalescent hospital 11 days after the operation.

In Dec. 1911 I saw the patient and questioned her carefully for any symptoms suggestive of primary and secondary growths in other organs, but could find nothing to make me think the tubal tumour other than the primary and only lesion. She said she was better than before the operation, but had still frequency of micturition and some vaginal discharge, which, however, was inoffensive and less copious. Pelvic examination failed to show any abnormality in the uterus or other appendages.

Since writing this I hear that the patient has been to the Infirmary again, and has now a definite swelling in the left of the pelvis palpable in the abdomen. She also has cedema of the left leg. There seems no doubt that the growth has recurred. 
Morbid anatomy. The naked eye appearance of the specimen as received from the operating theatre was that of a retort-shaped Fallopian tube showing a division into two distinct portions, namely, an outer bulbous extremity, closed, and about the size of a pigeon's egg, and an inner narrow portion approximating more nearly to the normal appearance. The tube was curved on itself, and was densely adherent to the ovary, which lay in its concavity, and the whole mass showed evidence of surrounding adhesions. On laying open the specimen the enlarged distal portion consisted of a friable, shaggy mass which filled the lumen and appeared to occupy nearly the whole thickness of the wall. It was, however, bounded peripherally by an obviously thickened peritoneal coat. The proximal portion appeared somewhat dilated; its wall was thicker than normal and the inner lining was smooth.

Histology. Sections have been taken (1) through the proximal portion of the tube; (2) at the junction of the healthier part of the tube and the tumour; (3) through the main mass of the tumour; and (4) through the ovary.

1. The proximal portion of the tube. The mucosa is here entirely replaced by a very vascular granulation tissue in which are numerous foci of round and plasma cells. The inner surface is smooth and lined by a fibro-cellular layer. The peritoneum is thickened and vascular, and foci of inflammatory cells are scattered throughout it as well as through the muscular layers.

2. At the junction of tumour and tube. As the region of the tumour is approached there is a gradual increase in the number of inflammatory cells in the mucosa, and an occasional outlying focus of round cells surrounding a small tumour mass is seen. The tumour itself begins abruptly, and is at once seen to be a cellular new growth heaped up above the level of the mucosa, replacing it entirely and infiltrating the superficial muscular layer. In structure it consists of solid masses and columns of cells with a more or less alveolar arrangement; in parts there is a villous appearance and the cells are placed at right angles to a central core of connective-tissue. There are large areas of necrosis, most of them situated in the centre of the solid masses. The cells for the most part are rounded and oval, with round, regular nuclei, varying but slightly in size and shape from one another; at first sight the appearance is that of a round-celled sarcoma. Here and there enormous cells occur, multinucleated or with single, oval, irregular nuclei more or less vesicular in character.

The stroma is cellular. It varies in amount in different parts, extending only as fine strands between the superficial masses of cells, but deeper down it is abundant and occurs as broad bands between the tumour masses. By means of Van Gieson's stain it is demonstrated that no stroma occurs between the individual cells of the growth. Blood-vessels are not numerous, and when they occur their 


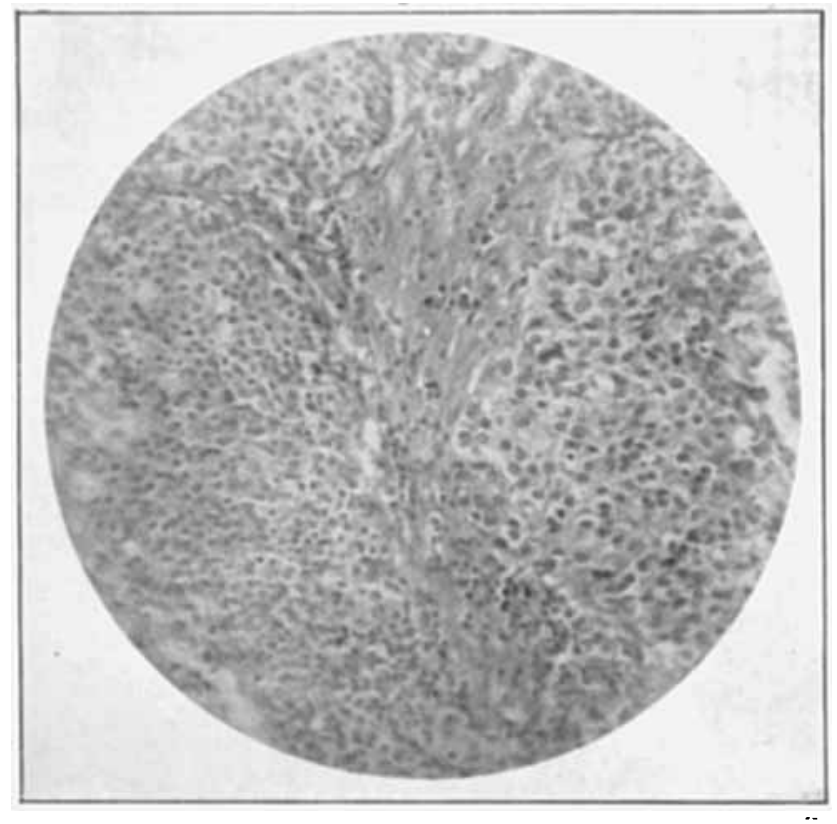

Fig. 1. Section through the nain mass of the tumour.

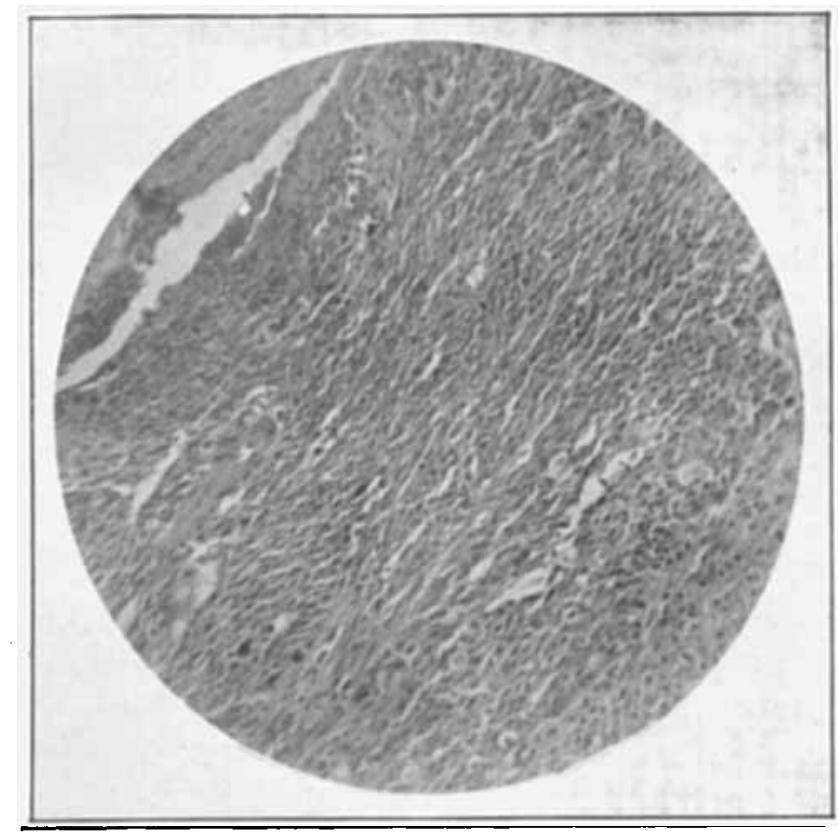

Fig. 2. The margin of section showing the elongated appearance of the cells 
walls are well formed. The peritoneal coat is distinctly thickened, and both it and the deeper muscle layers are invaded by foci of round cells. In the centre of some of these foci there are small masses of tumour sometimes apparently contained within a lymph channel; one such nodule is seen immediately beneath the peritoneum. Plasma cells are very numerous throughout the stroma of the growth as well as in the various layers of the tube.

3. Section through the centre of the growth shows much the same structure as that already described at the margin. It may be mentioned, however, that necrosis is more advanced and the arrangement of the cells is less readily defined.

In addition to this, one other point of great interest must be mentioned in connection with the structure of this tumour. At the margin of one of the sections there is an area of spindle-shaped tumour cells which have the exact appearance of a spindle-celled sarcoma; on careful examination it is seen that the oells of the stroma in this situation tend to be elongated, as do also many of the plasma cells, and this makes it probable that the spindle shape is merely due to pressure.

4. Section through the ovary shows a fibrotic change, but no evidence of involvement of the organ by new growth.

Commentary. It is difficult to determine the exact nature of this tumour. While the individual cells are like those of sarcoma the general arrangement is more like that of carcinoma. A consideration of the development of the Fallopian tube is of value. The Müllerian duct is of mesothelial origin. If then the lining of the fully-developed Fallopian tube is a direct derivative of this structure it follows that tumours arising from it are mesotheliomas. But, since the terms carcinoma and adenoma have merely a morphological significance, they may quite well be applied to the more highly differentiated members of this class, and need not be reserved for epiblastic or hypoblastic growths of similar structure. Adami* would avoid confusion by the use of such terms as mesothelial cancer, etc. Under these circumstances the term mesothelioma is best restricted (in the case of the Fallopian tube) to those transitional growths of indeterminate character such as the one just described; and I believe, after a careful perusal of the literature, that this is the term most applicable to many of the cases of so-called carcinoma or sarcoma of the Fallopian tube.

I may conclude by recapitulating a few of the other points of interest in this case. The tumour was unilateral; it was discovered in a woman three years after the menopause, and had given rise, among other symptoms, to pain and a watery vaginal discharge. The history points to a probable gonorrhœal infection more than 20 years

- Adami. Principles of Pathology, 19ro, vol. i, p. 708. 
before, in support of which there is histological evidence of chronic salpingitis probably of long duration. Alban Doran, ${ }^{*}$ in his summary of 100 cases of primary cancer of the Fallopian $\frac{1}{2}$ ube, gives it as his own opinion, as well as that of Orthmann, Sänger, Barth and Boxer, that cancer of the Fallopian tube is usually preceded by a chronic inflammatory lesion.

I wish to express my thanks to Dr. Hellier for his kind permission to use this case.

- A. Doran. "Cancer of Fallopian Tube." Journ. Obst. and Gyn., xgro, vol. xvii, pp. 7,8 . 